\title{
Exploring Differences in Amorphous Layer Formation during FIB Sample Preparation between Metals and Non Metals
}

\author{
Michael Presley ${ }^{1}$, Jacob Jensen ${ }^{1}$, Dan Huber ${ }^{1}$ and Hamish Fraser ${ }^{1}$ \\ 1. Center for the Accelerated Maturation of Materials, The Ohio State University, Columbus $\mathrm{OH}$
}

Over the last decade dual beam FIB has proved increasingly useful in a laboratory setting. Researchers have used dual beam FIB's in a wide variety of experiments, including but in no way limited to fabrication of nano pillars for micromechanical testing, modification of circuits during use, and the creation of tooling for nanoscale machining. The field of high resolution microscopy in particular has seen huge benefits from FIB processing in the form of high quality orientation specific lamella. One drawback of the technique is the formation of damage caused as a result of the impact of fast gallium ions on samples. This damage takes the form of the formation of lattice defects (e.g., dislocation loops) and/or amorphous layers on the surfaces of the FIB'd samples. The latter form of damage can degrade the quality of high resolution images and so the mechanism of its formation has been the subject of considerable study. However, these various studies of amorphization during FIB processing have largely focused on the effect of gallium ions on electronic materials. This concentration of research is likely due to several primary factors, the extensive use of and investment by the semiconductor industry in FIB research and the geometrical factors complicating measurement of amorphous damage. In our research, we have found that there are considerable differences between the amounts of amorphous damage between, on the one hand, semiconductors and, on the other hand, metallic materials. The present paper focuses on attempts to identify the origin for these differences.

The main problem in studying the formation of amorphous damage is the consistency in results as a function of the specifics of sample geometry. Most often, thin FIM lamellae are used, and the problem with the use of such samples is the difficulty in distinguishing between "primary" damage and redeposition of material that has been initially milled from the sample surface [1]. In the present study, needle shaped samples have been employed as these allow for consistent measurements of damage formation (as a function of sample thickness, which can be readily determined from the local diameter of the needle), and by positioning of a needle in close proximity to one being milled, the phenomenon of re-deposition can also be examined. Multiple needles may be made using a single FIB trenching operation. In this study one $28 \mu \mathrm{m} * 1.5 \mu \mathrm{m} * 4.5 \mu \mathrm{m}$ foil was sufficient to create six posts suitable for needle shaping and one slab suitable for creation of a TEM lamella. Redeposition was noted to be a major concern when making closely spaced needles, in Figure 1 over $45 \mathrm{~nm}$ of redeposition resulted from shaping a second needle $11 \mu \mathrm{m}$ from the first.

The use of needle-shaped samples has allowed for examination of amorphous layer damage in a variety of materials, most notably metals and intermetallics of interest for structural applications. Needles made from alloys of Ti 62222 and $\mathrm{Al} 7075$ [Figure 2(a)] using $30 \mathrm{kV}$ gallium ions had disordered or amorphized layers measuring $8 \mathrm{~nm}$ and $4 \mathrm{~nm}$ respectively. By comparison needles made at $30 \mathrm{kV}$ in silicon the average amorphous layer thickness was 25-30 nm [Figure 2(b)], and 5-8 nm thick when $5 \mathrm{kV}$ ions were used, in agreement with reported literature values [2]. Needles made at $30 \mathrm{kV}$ using NiAl and commercially pure metals such as $\mathrm{Ti}, \mathrm{Ni}, \mathrm{Al}$, and $\mathrm{Fe}$ all contained disordered layers with average thicknesses ranging from $\mathrm{a} \approx 2 \mathrm{~nm}$ to $\approx 8 \mathrm{~nm}$. 
Of particular interest to our research is the response of a compositionally complex alloy $\mathrm{Al}_{1} \mathrm{Mo}_{0.5} \mathrm{Nb}_{1} \mathrm{Ta}_{0.5} \mathrm{Ti}_{1} \mathrm{Zr}_{1}$ to FIB preparation using $30 \mathrm{kV}$ gallium ions. The alloy microstructure consists of two phases, an $\mathrm{Al}, \mathrm{Zr}$, Ti rich cuboidal and plate like $\mathrm{B} 2$ phase in a matrix of $\mathrm{Ta}$, Mo, and $\mathrm{Nb}$ rich $b c c$ phase. When viewed in HRTEM the amorphous layer thickness over the $b c c$ phase is on average 3-4 nm thick, showing good agreement with other metal thicknesses. However the other phase appeared to be fully amorphous well into the needle [Figure 2(c)]. The mechanism for such behaviour may possibly be related to differences in the role defect energies play in reaching a threshold for amorphization.

[1] S. Rajsiri et al, Microsc. Microanal. 8 (Suppl. 2), (2002) 50-51

[2] N. Kato, Journal of Electron Microscopy 53 (2004) 451-458

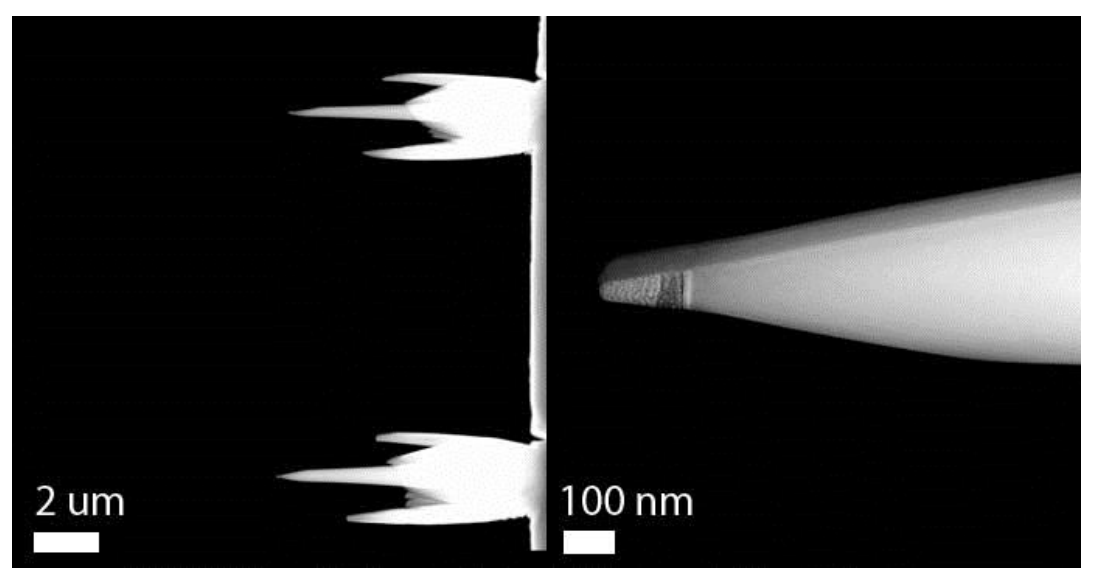

Figure 1. Redeposition from needle shaping in silicon

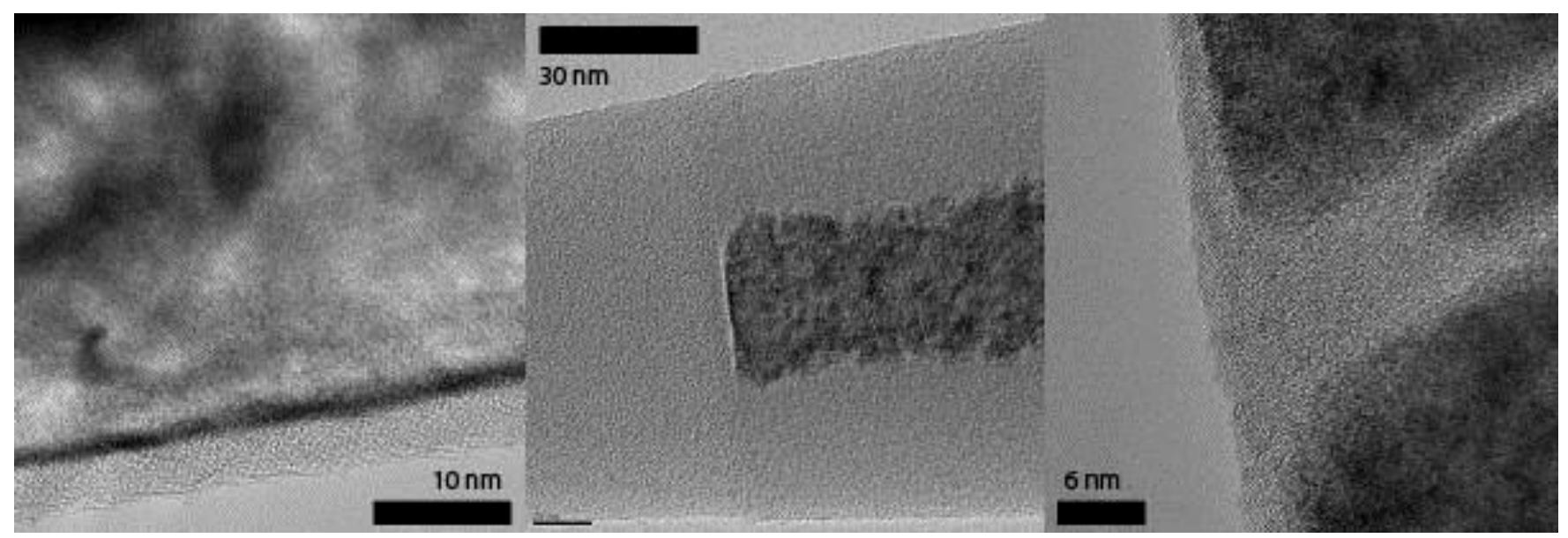

Figure 2. (a) $30 \mathrm{kV}$ damage layer in Al-7075, (b) $30 \mathrm{kV}$ damage layer in $\mathrm{Si}$, (c) Region of amorphous $\mathrm{B} 2$ phase in surrounding crystalline $b c c$ after $30 \mathrm{kV}$ shaping in $\mathrm{HEA} \mathrm{Al}_{1} \mathrm{Mo}_{0.5} \mathrm{Nb}_{1} \mathrm{Ta}_{0.5} \mathrm{Ti}_{1} \mathrm{Zr}_{1}$ 